\title{
Assessment of universal access to comprehensive sexual and reproductive health services in Egypt
}

\author{
Author: \\ Doaa Oraby ${ }^{1}$ \\ Affiliation: \\ ${ }^{1}$ Self-employed consultant, \\ Cairo-Egypt \\ Correspondence to: \\ Doaa Oraby \\ Email: \\ doaaoraby@yahoo.com \\ Postal address: \\ 6A Manial El Roda St. Apt. 17 \\ Cairo, Egypt \\ Dates: \\ Received: 01 May 2015 \\ Accepted: 11 Sept. 2015 \\ Published: 30 Sept. 2015 \\ How to cite this article: \\ Oraby, D., 2015, 'Assessment \\ of universal access to \\ comprehensive sexua \\ and reproductive health \\ services in Egypt', African \\ Evaluation Journal 3(2), Art. \\ \#147, 6 pages. http://dx.doi. \\ org/10.4102/aej.v3i2.147

\section{Copyright:} \\ (C) 2014. The Authors. \\ Licensee: AOSIS \\ OpenJournals. This work is \\ licensed under the Creative \\ Commons Attribution \\ License.
}

In 2005, a World Health Organization resolution called for health systems to move towards universal coverage, such that everyone would have access to promotive, preventive, curative and rehabilitative health interventions at an affordable cost. Responding to this call, a new target for achieving universal access to reproductive health was integrated within the revised millennium development goals framework. Forty-eight African countries adopted the Maputo Plan of Action committing to the goal of universal access to comprehensive sexual and reproductive health services in Africa by 2015. The aim of this study was to assess Egypt's commitment to implementing the Maputo Plan of Action. This was achieved through soliciting information relating to the extent of Egypt's progress towards the achievement of universal access to sexual and reproductive health and rights information and services. In late 2009 , a qualitative study was conducted. It included in-depth interviews with 20 physicians and 10 key informants in addition to 8 focus group discussions with sub-segments of 65 beneficiaries, including married women of reproductive age, married men and youth of both sexes. The study revealed that public sector, non-governmental organisations and private sector organisations delivering sexual and reproductive health services functioned in isolation from each other. Delivered services focused mainly on family planning and maternity care and targeted married women of reproductive age. Scaling up universal access to sexual and reproductive health services requires programmes to expand beyond the maternal and child health delivery model targeted solely at married women with children.

\section{Introduction}

\section{Background}

In 2005, a World Health Organization (WHO) resolution called for health systems to move towards universal coverage, such that everyone would have access to promotive, preventive, curative and rehabilitative health interventions at an affordable cost (WHO 2005) and under which healthcare benefits are distributed on the basis of need for care and not on ability to pay (Gwatkin et al. 2000). Responding to the WHO call, the new target for achieving universal access to reproductive health was integrated within the revised Millennium Development Goals (MDGs) framework (Mbizvo \& Zaidi 2010). Furthermore, ministers of health and delegates from 48 African countries (including Egypt) - who met in Maputo, Mozambique, in late 2006 adopted the Maputo Plan of Action (MPoA) ${ }^{1}$. The plan was intended to take the continent forward towards the goal of universal access to comprehensive sexual and reproductive health (SRH) services in Africa by 2015 whilst being broad and flexible to allow for adaptation at the national level (African Union Commission 2006).

Ensuring universal access to SRH services and information is essential for achieving many of the MDGs, especially those on maternal health, child survival, HIV and AIDS and gender equality. Fortunately, SRH for everyone is an achievable goal, provided cost-effective interventions are properly scaled up, political commitment is revitalised and financial resources are mobilised and more effectively used (Fathalla et al. 2006).

Egypt, which is a signatory to the MPoA, is a lower middle income country situated at the north-east corner of Africa, with a total area of 1000000 square kilometres and a population of 82637400 (Population Reference Bureau 2011). In Egypt, the Ministry of Health and Population (MOHP) is the government entity responsible for population policy and health. In addition to public health service providers, healthcare is also provided by non-governmental organisations (NGOs) and private hospitals and clinics (Ministry of Economic Development \& UNDP 2010). 1.The plan was built on nine action areas: integration of $\mathrm{SRH}$ services into primary healthcare, repositioning family planning, developing
and promoting youth friendly service, unsafe abortion, quality safe motherhood, resource mobilisation, commodity security and monitoring and evaluation. The plan is premised on SRH in its fullest context, taking into account the life cycle approach. 


\section{Literature review}

Egypt is on the right track towards realising most of the MDGs by the set date of 2015, but some regional disparities still need to be adequately addressed with rural Upper Egypt lagging behind. The 2008 Egypt Demographic and Health Survey (EDHS) revealed that the total fertility rate was 3.0 births per woman and that $57.6 \%$ of married women at the time of the survey were using modern non-traditional methods of contraception. The EDHS also demonstrated that the level of unmet need for family planning (FP) was $9 \%$ and was greatest (15\%) amongst women in rural Upper Egypt. However, almost $29 \%$ of women discontinue the use of modern contraceptive methods within 12 months of use, mostly due to reasons that could be avoided by proper counselling (El-Zanaty \& Ann 2009). With regard to maternal mortality, if the declining rate of maternal mortality is maintained, the targeted ratio for 2015 (43.5 deaths for every 100000 live births) will be achieved at the national level with few regional exceptions. The maternal mortality ratio has declined from 60.7 per 100000 live births in 2001 to 55.0 in 2009 and (El-Zanaty \& Ann 2009). However, coverage of maternity care services is especially inadequate in rural Upper Egypt, where regular antenatal care was received for $49 \%$ of births (Population Council 2010).

Not only is rural Upper Egypt still lagging behind regarding achieving the MDGs; so are slum areas. Egypt's slum areas increased from 1174 to 1210 between 2004 and 2006 and the share of urban population living in slums also increased by $3.5 \%$ during this period (WHO 2010). The slum areas and rural Upper Egypt mostly suffer from shortage of human resources (trained doctors, counsellors, nurses and midwives); medical services such as hospitals are mainly concentrated in urban areas and the cost of transport to regional hospitals prevents many poor people from accessing the appropriate facilities (Ministry of Economic Development \& UNDP 2010).

This study aims to assess Egypt's commitment to implementing the MPoA through soliciting information on Egypt's progress towards the achievement of universal access to SRH information and services. The results of the study synthesise recommendations meant to strengthen the health system and ensure universal access to SRH.

\section{Research method and design}

The current study was conducted in late 2009 in three governorates: Greater Cairo, Lower Egypt governorate and Upper Egypt governorate. The selection of governorates was intended to represent different geographic regions in the country. However, the frontier governorates were not represented due to time and budget constraints.

The assessment included desk review of existing reference documents, 10 in-depth interviews (IDIs) with key informants (from government, NGO, the private sector, United Nations agencies and other development partners) and 20 IDIs with physicians (affiliated to public, NGOs and private entities providing SRH services). The key informants and NGOs in the study governorates were asked to nominate physicians who could be interviewed. The physicians who agreed to participate were then interviewed by researchers. In addition, 8 focus group discussions (FGDs) were conducted with 65 participants representing sub-segments of the beneficiaries as follows: two with married women of reproductive age (MWRA), two with married men, two with young single men and two with young single women. The participants of FGDs were nominated by NGOs providing general community services within the study sites. The themes discussed during FGDs and IDIs included service integration, FP, quality safe motherhood, unsafe abortion and youth friendly services (YFS), whilst resource mobilisation, commodity security and monitoring and evaluation were also discussed with key informants.

Informed oral consent was obtained from participants of the FGDs and IDIs after researchers explained the purpose and procedures of the study, its voluntary nature, participants' right to withdraw or refuse to answer questions and attaining permission to record the interviews. Oral consent forms were used since the research presents no more than minimal risk of harm to subjects and involves no procedures for which written consent is normally required outside of the research context. The study team indicated in their notes that they presented the consent information and obtained oral consent. None of the study participants was younger than 18 years old; thus, no parent or guardian was approached for consent. Interviewees were assured that audiotapes would be saved in a secure place accessible only to the study team and would be destroyed once transcription was finalised. Interviewees were also assured that the audiotapes and transcripts would have no identifiers and that results would be presented in an aggregated form and could thus not be attributable to specific participants. Interviewees were also offered the opportunity to ask questions.

The respondents did not receive direct financial or any other material benefits for participating in the study. This was explained to them by the interviewer. For the participants of FGDs who needed to travel to a central place for the discussion session, a refund of double the local return bus fare was provided; this did not exceed the equivalent of US $\$ 5$.

IDIs and FGDs were transcribed verbatim and transcripts were checked against the audio recordings for accuracy. Patterns in and across the discussions were coded thematically. Data saturation was reached with the data presented here. Standard qualitative thematic analysis was applied to the FGD and IDI transcripts. The study protocol and instruments were developed and ethically approved by the SafAIDS review board and were adapted to the Egyptian context by a group of SRH experts in addition to representatives of the study participants. 


\section{Results}

Interviewed physicians and key informants stated that there were almost 5000 primary health care (PHC) units distributed in urban and rural areas that target MWRA. The services provided by these units included FP and maternal and child health $(\mathrm{MCH})$ services whilst delivery was not allowed except in hospitals equipped with blood banks.

Participants of FGDs perceived PHC units as credible places offering good quality FP services. Most of the MWRA stated that they were satisfied with the reasonable fees and felt at ease dealing with the female physicians who were available in almost all PHC units.

A married woman of reproductive age in one of the FGDs said: 'Family planning service is good and there is a female doctor.'

Some MWRA noted that they preferred FP services delivered by NGOs located in slums and rural areas and considered them to be of better quality than FP services delivered at PHC units and less expensive than those delivered by private clinics. Most MWRA noted that they did not usually access private facilities for FP methods owing to the high cost and predominance of male physicians in private facilities.

When asked about married men and single youth clients, physicians mentioned that these groups seldom accessed PHC units due to their reputation for mainly delivering FP and maternity services for MWRA. When probed about male clients suffering from sexually transmitted infections (STIs), physicians indicated that men suffering from STIs mostly resort to private entities or pharmacies. Concurrently, FGD male participants stated that when they or their friends suffer from STIs (burning sensation or discharge), they mostly consult a pharmacist who prescribes medications that often result in improvements. When probed, interviewed men clarified that pharmacists did not provide counselling or condom demonstration.

Desk review and key informants revealed that Egypt's population policy explicitly addressed young adults only through the provision of healthcare to girls prior to marriage and premarital examinations and counselling. The study found that YFS were not part of the PHC package and that the school health system did not systematically include SRH care for students. Interviewees and participants at FGDs stated that private hospitals and clinics did not offer YFS as they focused on income-generating activities (e.g. intrauterine device insertion, antenatal care and delivery). Interviews with key informants and physicians affiliated with youth friendly clinics (YFCs) demonstrated the availability of a small number of pilot YFCs mostly connected with NGOs but with uneven geographical distribution.

Interviewed physicians noted the underutilisation of the YFCs, which they attributed to inadequate promotion of clinics and the negative community attitude towards youth
SRH. Additionally, interviewed youth in FGDs who were familiar with YFC revealed that single men and women felt embarrassed about visiting the clinics as they were primarily known for delivering FP and maternal services to MWRA.

A young female FGD participant said: 'If a girl walks into an obstetrics and gynaecology clinic, people will be suspicious and wonder why she is going.'

As to HIV prevention and care services, IDIs with key informants revealed that they were mostly delivered through the National AIDS Program (NAP) and were not integrated at PHC level. Key informants justified that by Egypt's low HIV prevalence (below $0.02 \%$ ) amongst the general population (Ministry of Economic Development \& UNDP 2010). Physicians and the participants of FGDs indicated that they did not perceive the absence of HIV-related services at the PHC units as a drawback as they did not consider HIV to be a problem in Egypt. Almost all interviewed key informants and HIV physicians acknowledged that prevalent HIV-related stigma and discrimination prevented people living with HIV from disclosing their status or seeking out SRH services such as the voluntary counselling and testing (VCT) units, which are available free of charge. When the interviewers probed the knowledge of FGD participants regarding different VCT services (fixed or mobile), some could not identify the services whilst others referred to the 'Ask-Consult' slogan, which was a famous slogan for a successful FP campaign in Egypt in the 1980s.

As to the integration of HIV and SRH services, some of the key informants and interviewed physicians encouraged the integration, believing it would motivate married men and single youth to access PHC units and avoid feeling embarrassed about accessing units delivering only contraceptive and maternity services for MWRA. On the other hand, others believed that with a low-level HIV epidemic and prevalent HIV-related stigma, integration would not be cost effective and may even stigmatise and negatively influence the utilisation of PHC services. Alternatively, most interviewed youth recommended integrating YFS and menfocused services (specifically management of STIs) into PHC. They suggested devoting specific days or hours to men and youth to maintain their privacy and not embarrass MWRA who access the PHC units.

As to the issue of unsafe abortion, interviewed physicians and key informants stated that abortion is prohibited in Egypt unless medically indicated and, in such cases, it takes place under general or partial anaesthesia in well-equipped hospitals. Manual vacuum aspiration, an abortion procedure which can be performed in a clinic or doctor's office, had been implemented as a pilot project in selected hospitals to avoid the risk associated with general anaesthesia but had not yet been widely adopted. PHCs do not conduct medically indicated abortions as they lack the required resources but instead offer post-abortion care focusing on FP. Other cases of abortion (for example to terminate pregnancies resulting from rape or illegal relationships as well as abortions for 
economic or social reasons) could not take place at PHCs, or any other health facility, as these were not allowed by Egyptian law. Nonetheless, women found ways around these restrictions in order to end unwanted pregnancies. FGD participants indicated that poor young women who lacked the financial means often sought abortions at shady private clinics which were unsanitary and lacked essential supplies whilst well-to-do women resorted to certain private clinics and hospitals which had the necessary equipment in case of emergencies. Physicians at PHCs noted that they were sometimes approached by women concealing their unwanted pregnancy and requesting intrauterine device (IUD) insertion as a contraceptive method. These women were aware that IUD insertion would induce abortion. To rule out pregnancy, physicians revealed that they insist on inserting the IUDs only during a woman's menstruation.

An unexpected result of the assessment was the ignorance of almost all physicians regarding policies related to SRH and HIV. On the other hand, they underscored the policies related to improving their salaries and providing incentives based on their achievements.

Interviewed physicians and key informants noted that the low salaries and absence of benefits motivated highly qualified providers to seek opportunities outside the public health system. They added that the highly qualified providers usually work abroad or in the private sector with better pay either permanently, or whilst on leave from the public sector. Interviewees noted sadly that the public sector which provides affordable services to the poor - is usually left with less qualified staff or very young or very old service providers. Respondents also noted that the public sector appealed to women of child bearing age who benefit from the government's long maternity leave - something lacking in the private sector.

\section{Discussion}

Egypt's constitution provides for the protection of mothers, children and youth and guarantees the right of women to medical, physical, psychological and social healthcare (Supreme Council of the Armed Forces of Egypt 2011). Furthermore, Egyptian law does not put any condition or restriction on the delivery of SRH services in terms of age, sex or marital status. However, interviews with key informants and physicians revealed that the service request form at public entities included a husband's name cell implying that the service is limited to married women.

Ongoing funds are crucial to ensure universal access to SRH services. Studies revealed that for every dollar invested in FP in Egypt, US \$31 is saved (Susheela et al. 2004). Key informants partly attributed the improvements observed in FP and $\mathrm{MCH}$ related indicators in the past few decades to donor-funded programs. They stated that USAID provided the majority of support to Egypt's FP program contributing contraceptive supplies, training, information, education and communication support in addition to upgrading service sites and supporting policy and operations research support. However, in 2007 USAID provided its last supply of contraceptives to Egypt and responsibility for the supply of contraceptives was turned over to the government of Egypt and private sources. That was an area of concern for the key informants who were worried about the sustainability of the programme posing a major challenge in ensuring universal access to comprehensive SRH services.

Concurrently, affordability of services is essential to ensure universal access to SRH services specifically for the poorest people in societies. The poor are less motivated to report illnesses as they perceive them as a normal feature of life (Castro-Leal et al. 2000) or in order avoid taking time off income-generating activities (Sauerborn, Adams \& Hien 1996). Regular antenatal care was received for just over $40 \%$ of births to women in the lowest wealth quintile, compared to nearly $90 \%$ of births to women in the highest quintile. The proportion of births assisted by a medical provider was $55 \%$ in the lowest quintile and $97 \%$ in the highest quintile (Population Council 2010). The assessment revealed that FP and maternity care services were offered at a fair price in public and NGO sectors which was noted by the interviewees. On the other hand, the cost of transport from rural areas lacking health facilities to the facilities in urban areas prevented many poor people from accessing the appropriate facilities.

Although the interviewees and FGD participants did not encourage integrating HIV services into PHC units, targeting men and youth through prevalent PHC units presented a missed opportunity for HIV prevention through promoting safe sexual behaviour, managing STIs and increasing condom use. Married and single men in the FGDs stated that they resorted to pharmacies or private clinics in case of STIs where they were usually prescribed medications. However, they revealed that neither pharmacists nor private physicians provided counselling or prescribed and performed condom demonstrations and none of them was referred to a VCT unit. The results of the 2006 and 2010 Biological and Behavioral Surveillance Surveys revealed a concentrated HIV epidemic amongst some high-risk groups (MOHP \& NAP 2006; MOHP, FHI \& CDS 2010). Hence, Egypt should adopt steps to improve accessibility of SRH services to married men and youth and avoid experiencing an increase in HIV incidence amongst this group.

The assessment revealed that cultural values and traditions influenced utilisation of SRH services. This was demonstrated through preference of places with a female physician by MWRA where an interviewed female physician attended to around 20 clients per day compared to around 3 clients per day attended to by an interviewed male physician. Women generally preferred to see female healthcare providers, but few competent ones were available in rural Upper Egypt thus negatively influencing the accessibility of SRH services. Some MWRA added that they resorted to private clinics run mostly by male doctors only in the case of a high-risk pregnancy, 
infertility or, as one respondent put it, 'a complicated case that needs experienced and competent specialist'.

The study reflected that the attitude of physicians was of utmost importance in accessing SRH services. The Code of Ethics of Profession in Egypt allows doctors to deny patients services that contradict their religious or cultural beliefs except in cases of emergency. ${ }^{2}$ Most of the interviewed physicians stated that attending to youth practising premarital sex was in opposition to their cultural and religious norms and could be negatively interpreted by the surrounding community as an approval of illicit behaviour. This could partly explain why youth were not seeking SRH services at public entities and why YFCs were underutilised, regardless of the absence of an enabling environment and adequate promotion. The situation of youth accessibility to SRH services was further worsened by the fact that the school health insurance system did not include SRH care for students and no SRH program existed for out-of-school youth (Lane, Mouelhy \& Jok 1998).

Another factor influencing accessibility to SRH services is physicians' continuous turnover. Human resource regulations oblige physicians to take up a position at a public facility for a certain amount of time. Once at the facilities, the low salaries and absence of benefits motivate highly qualified physicians to seek opportunities with better pay either in the private sector or abroad. The established rapport and bond between service provider and client is a crucial factor in motivating clients' utilisation of services as revealed through FGDs and IDIs that pointed out that the turnover problem was more pronounced in rural Upper Egypt. The shortage of physicians in Upper Egypt could also be attributed to the uneven geographical distribution of the medical universities. This problem was reflected by the 2008 EDHS which revealed differentials of FP and $\mathrm{MCH}$ indicators by region of residence with rural Upper Egypt lagging behind the other regions.

\section{Limitations of the study}

The current study was conducted in late 2009; hence, the challenges in universal access to SRH influenced by the continued political turmoil in Egypt since 2011 are not part of this article. The researcher tried to include beneficiaries from different socioeconomic backgrounds in the FGDs for better insight into universal access to SRH services. However, the influence of the socioeconomic factors on the accessibility of SRH services was beyond the scope of this study. Lastly, owing to time and budget constraints, frontier governorates were not represented in the study.

Another limitation of the study was the researchers' inability to get the study approved by an Egyptian Ethical review board. The reasons for this were as follows: (1) the study was not eligible for review by the ethics committees of Egyptian universities as it was not being conducted in collaboration with them and (2) the ethics review committee of the MOHP required a very high fee (equivalent to US\$2000 in 2009) to process the ethics clearance request - an amount the study team could not come up with as it had not been included in the study budget. As an alternative, the study protocol and instruments (previously approved by the SafAIDS ethical review board) were adapted to the Egyptian context by a group of SRH experts as well as representatives from the study participants who were excluded from the data collection activities yet did not limit the number of participants who were available for the study.

\section{Conclusion}

The assessment revealed positive aspects observed in improved FP and $\mathrm{MCH}$ related indicators in the past few decades in addition to some negative aspects that require attention to ensure universal access to SRH services. One of the main shortcomings requiring immediate attention was the absence of coordination amongst the public sector organisations, NGOs and private sector organisations that deliver SRH services but function as isolated islands. Another shortcoming was that delivered SRH services focused on FP and $\mathrm{MCH}$ and targeted MWRA whilst married men and single youth of both sexes were left behind. This negligence resulted in wives carrying the burden of contraception alone and a society which did not acknowledge youth's need for SRH services and information.

Achieving universal access to SRH information and services requires developing partnerships between governmental agencies, the private sector and NGOs through publicprivate partnerships to complement each other as regards their scope of activities and areas of coverage, with special focus on addressing the needs of the poor in remote areas. Furthermore, achieving universal access to SRH services implies that programmes must move away from the FP and $\mathrm{MCH}$ delivery model and the almost exclusive orientation towards married women with children. Special attention should be given to encouraging men to take responsibility and become full partners in the SRH of their families and to educating youth about their SRH. Last but not least, ensuring universal access to SRH implies informing and mobilising the community to raise awareness and create a supportive environment for YFS.

\section{Acknowledgements}

This study was supported by SafAIDS through a grant provided by the Ford Foundation number 1095-0481. The author wishes to acknowledge the interviewed physicians, key informants and beneficiaries whose positive attitude and openness have been remarkable.

\section{Competing interests}

The author declares that she has no financial or personal relationship(s) that may have inappropriately influenced her in writing this article. 


\section{References}

African Union Commission, 2006, Maputo Plan of Action for the operationalization of the continental policy framework for sexual and reproductive health and rights (2007-2010), viewed 10 October 2009, from http://www.unfpa.org/africa/ newdocs/maputo_eng.pdf

Castro-Leal, F., Dayton, J., Demery, L. \& Mehra, K., 2000, 'Public spending on health care in Africa: Do the poor benefit?', Bulletin of the World Health Organization 78(1), 66-74. PMID: 10686734.

El-Zanaty, F. \& Ann, W., 2009, Egypt demographic and health survey 2008, Ministry of Health, El-Zanaty and Associates and Macro International, Cairo.

Fathalla, M.F., Sinding S.W., Rosenfield, A. \& Fathalla M.M., 2006, 'Sexual and reproductive health for all: A call for action', The Lancet 368(9552), 2095-2100. PMID: 17161731.

Gwatkin, D., Rutstein, S., Johnson, K., Suliman, E., Wagstaff, A. \& Amouzou, A., 2000 Socioeconomic differences in health, nutrition and population, The World Bank, Washington, DC.

Lane, S.D., Jok, J.M \& Mouelhy, M.T., 1998, 'Buying safety: The economics of reproductive risk and abortion in Egypt', Social Science and Medicine 47(8), 1089-1099. PMID: 9723854.

Mbizvo, M.T. \& Zaidi, S., 2010, 'Addressing critical gaps in achieving universal access to sexual and reproductive health $(\mathrm{SRH})$ : The case for improving adolescent SRH, preventing unsafe abortion, and enhancing linkages between SRH and HIV interventions', International Journal of Gynecology and Obstetrics 110, S3-S6. PMID: 20451907, http://dx.doi.org/10.1016/j. ijgo.2010.04.001
Ministry of Economic Development \& United Nations Development Program (UNDP), 2010, Egypt's progress towards achieving the millennium development goals, UNDP, Cairo.

Ministry of Health and Population (MOHP), Family Health International (FHI) \& Center for Development Services (CDS), 2010, Egypt biological and behavioral surveillance survey - Summary report, MOHP, Cairo.

MOHP \& National AIDS Program (NAP), 2006, HIV/AIDS biological and behavioral surveillance survey 2006 - Summary report, MOHP, Cairo.

Population Council, 2010, Survey of the young people in Egypt, Population Council, Cairo.

Population Reference Bureau, 2011, World population data sheet, Population Reference Bureau, Washington, DC.

Sauerborn, R., Adams, A. \& Hien M., 1996, 'Household strategies to cope with the economic costs of illness', Social Science and Medicine 43, 291-301. PMID: 8844932, http://dx.doi.org/10.1016/0277-9536(95)00375-4

Supreme Council of the Armed Forces of Egypt, 2011, Constitutional declaration 2011, article 10, viewed 22 July 2012, from http://www.egypt.gov.eg/english/ laws/constitution

Susheela, S., Jacqueline, E., Michael, V. \& Jennifer N., 2004, Adding it up: The benefits of investing in sexual and reproductive health care, Alan Guttmacher Institute and UNFPA, Washington, DC, \& New York, NY.

World Health Organization (WHO), 2005, Social health insurance: Sustainable health financing, universal coverage and social health insurance, 58th World Health Assembly, Geneva, 16-25 May, 2005.

World Health Organization, 2010, Country cooperation strategy for WHO and Egypt (2010-2014), WHO/EMRO, Cairo. 